\title{
Endoscopic hemostasis treatment: How should you perform it?
}

\author{
Julia J Liu MD FRCPC FACP FACG ${ }^{1}$, John R Saltzman MD FACP FACG ${ }^{2}$
}

$\mathrm{N}$ onvariceal upper gastrointestinal (GI) bleeding represents thousands of emergency room visits and hospitalizations annually, with an overall mortality rate of $5 \%$ to $10 \%$ despite advances in medical and endoscopic therapies (1). Endoscopy is the primary modality for accurate diagnosis and treatment of upper GI hemorrhage. The diagnostic accuracy of upper endoscopy is more than $95 \%$. Aggressive initial resuscitation is essential for good patient outcomes and must be performed independent of the time to upper endoscopy.

\section{IMPROVING VISUALIZATION OF THE BLEEDING SITE}

One of the main challenges in the management of upper GI bleeding is the clearing of blood and clots to allow for adequate visualization of the bleeding site. Gastric lavage before

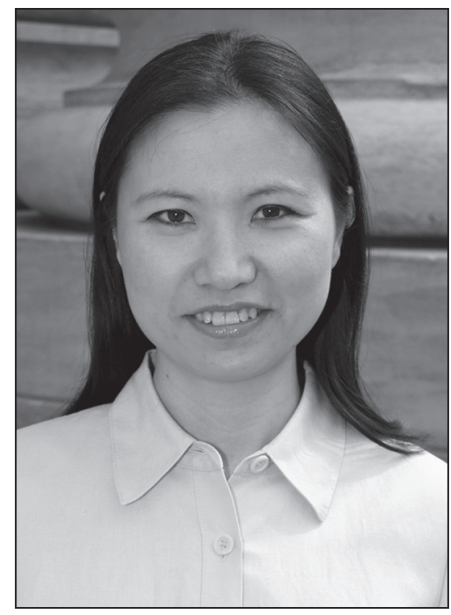

Dr Julia Liu is a gastroenterologist at the University of Alberta Hospital, Edmonton, Alberta presentation) have shown that urgent endoscopy reveals more high-risk lesions $(4,5)$. However, the time to endoscopy did not influence the outcome of patients in these studies, reflecting that morbidity and mortality associated with upper GI bleeding are more likely to be influenced by the underlying disease of the patient, and the adequacy of initial resuscitation rather than the time to endoscopy. Early upper endoscopy should be performed after stabilization of the patient.

\section{MANAGEMENT OF BLEEDING PATIENTS ON ANTICOAGULANTS}

There are limited data available to guide the endoscopic management of patients on anticoagulation therapy presenting with upper GI bleeding. A retrospective review of 233 patients (6) with nonvariceal upper GI bleeding found that the presence of mild to moderate anticoagulation did not alter the outcome of endoupper endoscopy is the conventional method of improving visualization, but is cumbersome to perform and often not effective in removing all of the gastric contents. More recently, intravenous erythromycin ( $250 \mathrm{mg}$ intravenous bolus or $3 \mathrm{mg} / \mathrm{kg}$ over $30 \mathrm{~min}$ ) has been shown to improve the diagnostic yield of diagnostic upper endoscopy and is comparable with gastric lavage $(2,3)$. Intravenous erythromycin is relatively safe to administer and may reduce the risk of aspiration associated with gastric lavage. Erythromycin can be given at between $30 \mathrm{~min}$ to $2 \mathrm{~h}$ before endoscopy. In patients with major upper GI bleeding, including those presenting with hematemesis, we will consider the use of intravenous erythromycin before upper endoscopy. In patients who undergo upper endoscopy with unexpected findings of large amounts of blood in the stomach obscuring the source of bleeding, endoscopy can be terminated and intravenous erythromycin administered. A repeat upper endoscopy following the erythromycin infusion will offer much improved visualization of the area.

\section{THE TIME TO UPPER ENDOSCOPY}

Another factor that may also influence the identification of the bleeding site is the time to endoscopy. Urgent endoscopy has been shown to increase the diagnostic accuracy of the bleeding source. Retrospective reviews of patients who underwent urgent endoscopy (defined as within $6 \mathrm{~h}$ to $8 \mathrm{~h}$ of presentation of upper GI bleeding) or elective endoscopy (up to $48 \mathrm{~h}$ after scopic intervention. Thus, therapeutic upper endoscopies appear to be effective in patients who are mild to moderately anticoagulated. However, further studies are needed to determine the effect of antiplatelet agents (such as clopidogrel) on endoscopic interventions. We recommend endoscopic hemostasis for nonvariceal upper GI bleeding in patients who are mildly to moderately anticoagulated and to withold antiplatelet agents if possible.

\section{THERAPEUTIC ENDOSCOPIC MODALITIES}

The current endoscopic modalities to treat nonvariceal upper GI bleeding include injection therapy (typically of diluted adrenaline), thermal coagulation therapy and mechanical treatments (clips and band ligators). Combination of any of the treatment modalities, usually injection along with another modality, is a commonly used hemostasis technique for control of nonvariceal upper GI bleeding.

Injection of diluted adrenaline $(1: 10,000$ to $1: 20,000$ dilution) for endoscopic hemostasis treatment is the oldest endoscopic hemostasis method, with typical injection volumes of less than $10 \mathrm{~mL}$. There is evidence that using higher volumes (eg, $20 \mathrm{~mL}$ to $40 \mathrm{~mL}$ ) for injection therapy may be more efficacious at reducing rebleeding than the conventional relatively low volume, although overall clinical outcomes including surgery rates and mortality have not been shown to be improved (7).

${ }^{1}$ University of Alberta Hospital, Edmonton, Alberta; ${ }^{2}$ Brigham and Women's Hospital, Harvard Medical School, Boston, Massacheusetts, USA

Correspondence: Dr Julia J Liu, University of Alberta Hospital, Zeidler Ledcor Centre, Edmonton, Alberta T6G 2 X8.

Telephone 780-492-6874, fax 780-492-7115, e-mail julia.liu@ualberta.ca

Received and accepted for publication June 17, 2009 
Higher doses of injected adrenaline are more likely to cause cardiovascular side effects, particularly when injected around the region of gastroesophageal junction and the distal esophagus. Overall, injection monotherapies are believed to be inferior to other monotherapies for control of upper GI bleeding and are not currently recommended (8). In most clinical scenarios, injection therapy should be used only in conjunction with other modalities to control GI bleeding.

Thermocoagulation therapies to control nonvariceal upper GI hemorrhage include bipolar and monopolar cautery probes as well as noncontact thermal methods such as argon plasma coagulation. Bipolar thermal cautery probes are the most commonly used and do not require a grounding pad. The bipolar probe can be applied perpendicularly or tangentially to coagulate the bleeding site. The bleeding vessel is compressed and cauterized (coaptive coagulation) to provide full thermal coagulation to seal the bleeding vessel. The bipolar coagulation probes are available in two sizes, $7 \mathrm{Fr}$ and $10 \mathrm{Fr}$. The larger probes are believed to be more effective but require the use of a larger therapeutic endoscope. Relatively low wattages of $15 \mathrm{~W}$ to $20 \mathrm{~W}$ are typically recommended with prolonged $8 \mathrm{~s}$ to $12 \mathrm{~s}$ pulses per treatment, with mild to moderate pressure applied for effective hemostasis. Four to six pulses are usually needed to achieve the end point of target vessel flattening with no evidence of further bleeding. Combination therapies are believed to be clinically superior to injection therapy alone, with reduced rebleeding. A comparison study of adrenaline injection alone versus bipolar cautery alone versus combination of injection and bipolar cautery therapy showed similar initial hemostasis success, but a significant reduction in rate of rebleeding in the combination therapy group (9). We recommend the use of the combination therapy as an effective treatment of nonvariceal upper GI bleeding.

Other thermal coagulation methods such as monopolar coagulation and directed, noncontact thermal methods such as argon plasma coagulation are also available for clinical use. Clinical experience and data for endoscopic hemostasis with monopolar cautery devices are limited. For noncontact thermal methods, argon plasma coagulation has been predominantly used. Beneficial effects of argon plasma coagulation have been demonstrated for focal vascular ectasias, gastric antral vascular ectasia (watermelon stomach) (10) and Dieulafoy's lesions (11).

Endoscopic clips are mechanical compression devices available for the management of nonvariceal upper GI bleeding. Endoscopic clips function by mechanical compression of the bleeding vessel and theoretically cause less tissue injury than cautery methods. Comparative studies (12) of endoscopic clips to conventional injection plus bipolar thermal cautery have shown a similar efficacy rate of initial hemostasis. A

\section{REFERENCES}

1. Muller T, Barkun AN, Martel M. Non-variceal upper GI bleeding in patients already hospitalized for another condition. Am J Gastroenterol 2009;104:330-9.

2. Frossard JL, Spahr L, Queneau PE, et al. Erythromycin intravenous bolus infusion in acute upper gastrointestinal bleeding: A randomized, controlled, double-blind trial. Gastroenterology 2002;123:17-23.

3. Coffin B, Pocard M, Panis Y, et al. Erythromycin improves the quality of EGD in patients with acute upper GI bleeding: A randomized controlled study. Gastrointest Endosc 2002;56:174-9. meta-analysis of 15 randomized control trials of 1156 patients (13) showed that definitive hemostasis was achieved in $87 \%$ of subjects with endoscopic clips and in $75 \%$ of individuals who underwent injection therapy. The rebleeding rate was $10 \%$ in the endoscopic clip group and $20 \%$ in the injection therapy group; the surgery rate was $2 \%$ for the clip group and $7 \%$ for the injection therapy group. However, when clips were compared with thermocoagulation monotherapies and combination therapy, there was no difference in efficacy. Endoscopic clips can be placed with or without injection of adrenaline. Injection before clip placement can be helpful in patients with active GI bleeding to slow the bleeding and allow for better localization and targeting of the clip. Residual oozing after clip placement can also be treated with injection of dilute adrenaline. The type and location of a bleeding lesion is a major factor in determining whether we use thermocoagulation combination therapy or endoscopic clips. Endoscopic clips are our first choice for hemostasis control in ulcers with a visible vessel or with active bleeding if the lesion is in a location amenable to this therapy (more difficult when retroflexed in the stomach or in a curve of the duodenum).

\section{SECOND-LOOK ENDOSCOPY}

After achieving initial hemostasis, a second-look endoscopy (ie, repeat hemostasis if persistent stigmata of recent hemorrhage are present) at between $24 \mathrm{~h}$ to $48 \mathrm{~h}$ after the initial upper endoscopy is routinely performed in some endoscopy centres. In most areas where second-look endoscopy is routinely practiced, injection of adrenaline as monotherapy is used for endoscopic hemostasis, which has a higher rebleeding rate than with monotherapy using cautery or clips, or with combination therapy. The value of second-look endoscopy has been studied in a randomized controlled trial (14) of patients who underwent combination therapy with adrenaline and bipolar cautery therapy. This study demonstrated the benefit of second-look endoscopy (and second therapeutic endoscopy if endoscopic stigmata of bleeding are seen) at reducing rebleeding and surgery rates. Although second-look endoscopy is not beneficial in most patients, we believe it should be considered in patients with high-risk lesions or lesions that are difficult to treat, and for patients with multiple comorbidities.

\section{CONCLUSIONS}

Optimal management of patients with acute nonvariceal upper GI bleeding requires aggressive initial resuscitation. Upper endoscopy is highly accurate at diagnosing the source of bleeding when performed early in the clinical course and when visualization is adequate. Therapeutic endoscopy with current proven therapies is effective at stopping initial bleeding and reducing rebleeding.

4. Tai CM, Huang SP, Wang HP, et al. High-risk ED patients with nonvariceal upper gastrointestinal hemorrhage undergoing emergency or urgent endoscopy: A retrospective analysis. Am J Emerg Med 2007;25:273-8.

5. Targownik LE, Murthy S, Keyvani L, Leeson S. The role of rapid endoscopy for high-risk patients with acute nonvariceal upper gastrointestinal bleeding. Can J Gastroenterol 2007;21:425-9.

6. Wolf AT, Wasan SK, Saltzman JR. Impact of anticoagulation on rebleeding following endoscopic therapy for nonvariceal upper gastrointestinal hemorrhage. Am J Gastroenterol 2007;102:290-6. 
7. Park CH, Lee SJ, Park JH, et al. Optimal injection volume of epinephrine for endoscopic prevention of recurrent peptic ulcer bleeding. Gastrointest Endosc 2004;60:875-80.

8. Park WG, Yeh RW, Triadafilopoulos G. Injection therapies for nonvariceal bleeding disorders of the GI tract. Gastrointest Endosc 2007;66:343-54.

9. Lin HJ, Tseng GY, Perng CL, Lee FY, Chang FY, Lee SD.

Comparison of adrenaline injection and bipolar electrocoagulation for the arrest of peptic ulcer bleeding. Gut 1999;44:715-9.

10. Herrera S, Bordas JM, Llach J, et al. The beneficial effects of argon plasma coagulation in the management of different types of gastric vascular ectasia lesions in patients admitted for GI hemorrhage. Gastrointest Endosc 2008;68:440-6.
11. Iacopini F, Petruzziello L, Marchese, et al. Hemostasis of Dieulafoy's lesions by argon plasma coagulation (with video). Gastrointest Endosc 2007;66:20-6.

12. Saltzman JR, Strate LL, Di Sena V, et al. Prospective trial of endoscopic clips versus combination therapy in upper GI bleeding (PROTECCT-UGI bleeding). Am J Gastroenterol 2005; 100:1503-8.

13. Sung JJ, Tsoi KK, Lai LH, Wu JC, Lau JY. Endoscopic clipping versus injection and thermocoagulation in the treatment of nonvariceal upper gastrointestinal bleeding: A meta-analysis. Gut 2007;56:1364-73.

14. Chiu PW, Lam CY, Lee SW, et al. Effect of scheduled second therapeutic endoscopy on peptic ulcer rebleeding: A prospective randomised trial. Gut 2003;52:1403-7. 


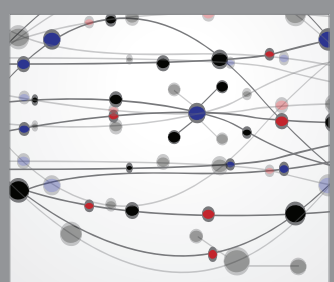

The Scientific World Journal
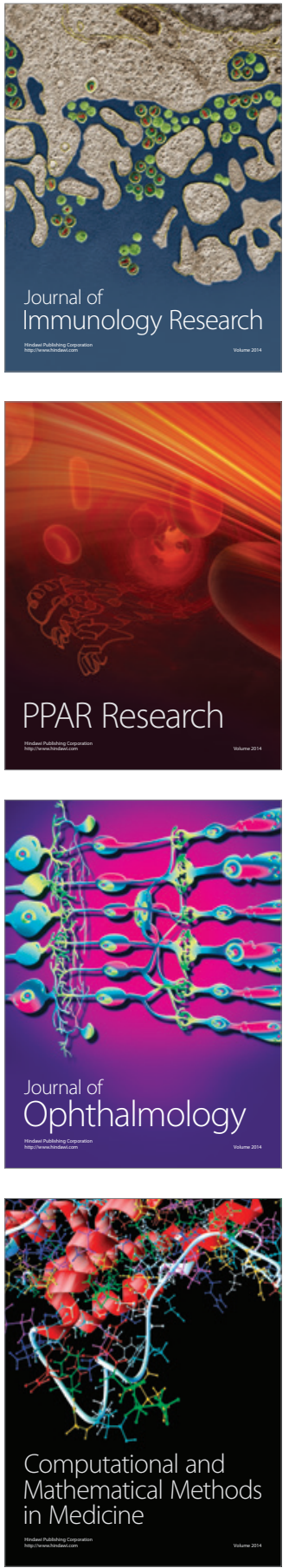

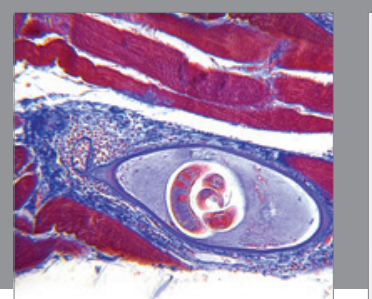

Gastroenterology Research and Practice

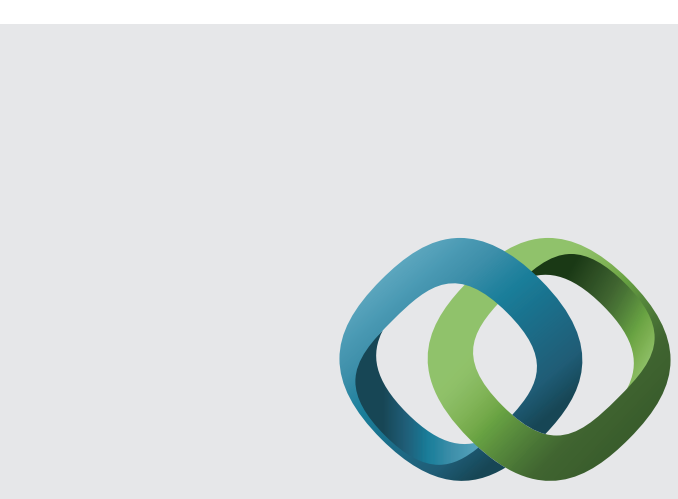

\section{Hindawi}

Submit your manuscripts at

http://www.hindawi.com
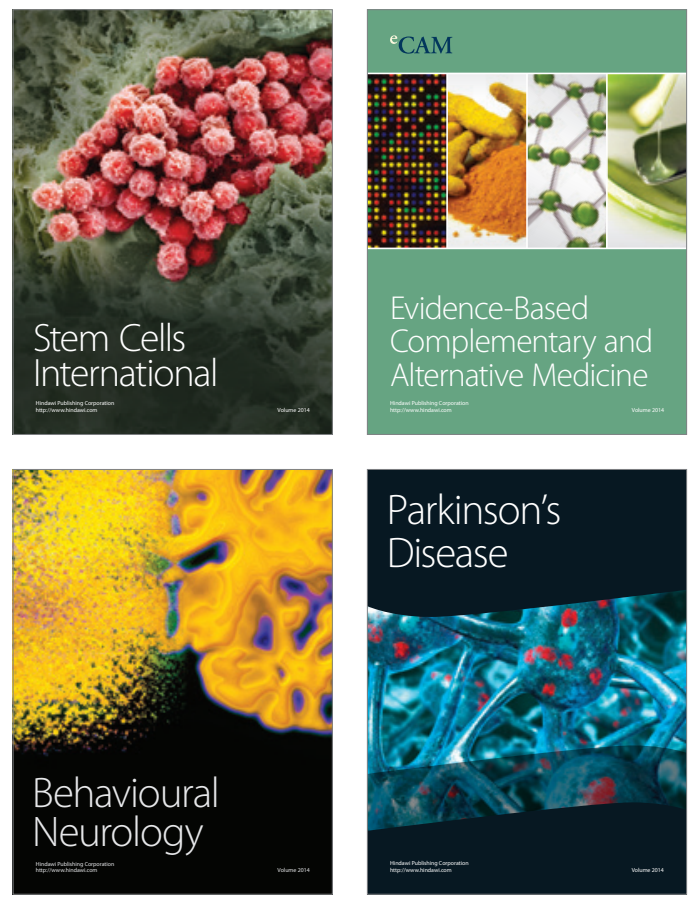
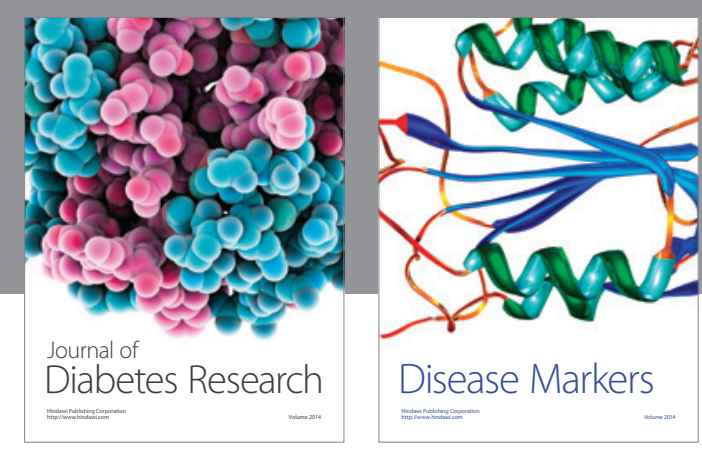

Disease Markers
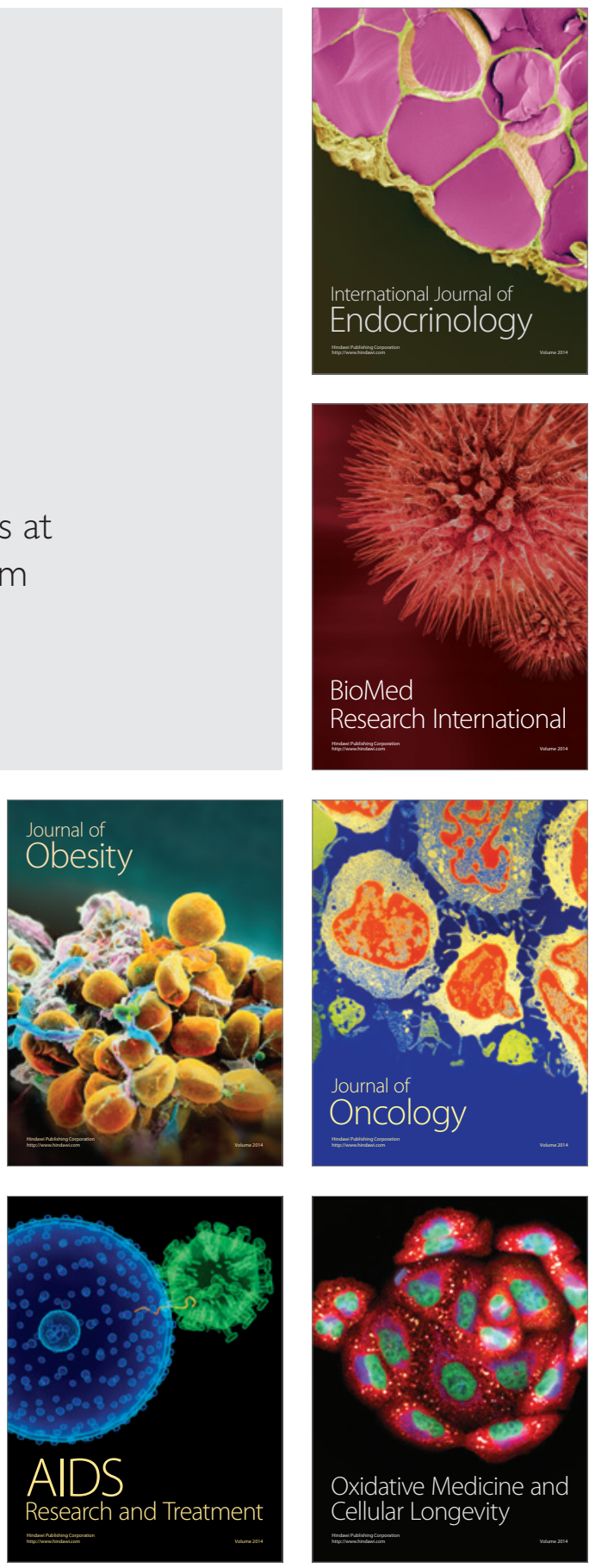